\title{
The sexual rights of people with physical and psychical disa- bilities: attitudes of Italians and socio-demographic factors in- volved in recognition and denial
}

\author{
Simona Gabriella Di Santo ${ }^{1,2,}$, Margherita Colombo ${ }^{3^{*}}$, Marco Silvaggi ${ }^{4}$,Giorgia Rosamaria Gammino ${ }^{5}$, Valentina \\ Fava $^{6}$, Chiara Malandrino ${ }^{6}$, Chiara Nanini ${ }^{7}$, Cristina Rossetto ${ }^{8}$, Sara Simone ${ }^{9}$, and Stefano Eleuteri ${ }^{10,11}$
}

\author{
IRCCS Fondazione Santa Lucia via Ardeatina 30600179 Roma; s.disanto@hsantalucia.it \\ Italian Association of Applied Sexology and Psychology (AISPA) via Marostica 3520146 Milano; \\ s.disanto@hsantalucia.it \\ 3 Superior School of Clinical Sexology of Turin Via Unione Sovietica 33510135 Torino; mar- \\ gher-c79@libero.it \\ 4 Institute of Clinical Sexology (ISC) Via Savoia 78, 00198 Roma; m.silvaggi@gmail.com \\ $5 \quad$ Italian Center of Sexology (CIS) Via Col del Rosso 735141 Padova; g.r.gammino@gmail.com \\ 6 Research group for sexology. Via S. Sofia 7895123 Catania; valentinafavamp4@yahoo.it ; \\ chiaramalandrino@yahoo.it \\ 7 Interdisciplinary Centre for Research and Training in Sexology (CIRS) Via Angelo Ceppi di Bairolo 1/8 \\ 16126 Genova; chiarananini@virgilio.it \\ 8 Study Center for Affective and Sexual Disorders Treatment (DAS) Via G.T. Invrea 20/2 16129 Genova; \\ cristinarossetto@icloud.com \\ $9 \quad$ Institute of Research and training (IRF) Via Luigi Alamanni 2350123 Firenze; sarasimone77@hotmail.com \\ 10 World Association of Sexual health; stefano.eleuteri@uniroma1.it \\ 11 Faculty of Medicine an Psychology, Sapienza University of Rome; stefano.eleuteri@uniroma1.it \\ * Correspondence: SGDS: s.disanto@hsantalucia.it ; Tel.: +39 0651501177 \\ MC: margher-c79@libero.it; Tel.: +39 3471041270
}

\begin{abstract}
The aims of this study were to analyze the level of agreement of a sample of Italian people with some of the sexual rights (SRs) of people with physical and psychical disabilities (PwPHDs and PwPSYDs), to inquire if PwPSYDs were subject to less recognition than PwPHDs, and if socio-demographic characteristics, such as age, sex, education, occupation, geographical origin, relational status, sexual orientation, and religiosity, associated with being against these SRs. The level of agreement or disagreement (on a 6-point Likert scale) with statements regarding the right of PwPHDs and PwPSYDs to have a satisfying sexuality, to marry, to adopt a child, was inquired with an online anonymous questionnaire. 973 participants, aged $18-84$ years $(71.1 \%$ females $)$ were considered for analyses; At least 7 out of 10 participants declared in favor of the SRs of PwPHDs, while the SRs of PwPSYDs were always subjected to higher underrecognition. Religiosity almost invariably associated to being against the SRs of PwDs. Being male, of higher age and lower education also associated with lower recognition. A better identification of the less tolerant respondents and of the less recognized categories may allow for specific strategies for promoting the recognition of the SRs for PwDs.
\end{abstract}

Keywords: sexual rights, physical disabilities, psychical disabilities, sexual minorities, societal attitudes

\section{Introduction}

More than $15 \%$ of the world's population are affected by disabilities, including physical and sensory impairments, developmental and intellectual disabilities and psychosocial disabilities[1]. Disabilities are defined by the UN Convention on the Rights of Persons with Disabilities (UNCRPD) as the presence of long-term physical, mental, intellectual or sensory impairments, which in interaction with various barriers may hinder their full and effective participation in society on an equal basis with others[2]. Disabilities, therefore are 
not caused by the impairments themselves, but rather by the presence of barriers in the physical environment, access to information and education, laws and norms, services and societal beliefs and behaviors[3].

One main barrier that people with disabilities (PwDs) - and in particular those with psychical and intellectual impairments - are still forced to face, concerns the full realization of their sexual rights (SRs). SRs are today considered fundamental human rights, and their violation constitutes a violation of the rights to equality, non-discrimination, dignity and health[4]. The SRs of PwDs in relation to marriage, family, parenthood, relationships, fertility, access to information and sexual and reproductive health services and freedom from exploitation and abuse are supported at the institutional level[1,2] Despite this, the sexual rights of people with disabilities struggle to be recognized in societies, often due prejudices and stereotypes. Stereotypes associated with PwDs presume that they are childlike, not sexually attractive, with underdeveloped or abnormal sexual desires, and maladjusted to any kind of sexual expression[5]. "Myths" about disability include prevalent and related false beliefs, such as the 'myth of physical perfection'[6] which considers PwDs as not sexually attractive; the 'myth of asexuality'[7,8], which elicit perceptions of vulnerability, childlike innocence, and dependency, and justifies the presumption of an absence of affective and erotic experiences in PwDs, who are seen as holy innocents disinterested in sex; the 'fucking ideology[7] which considers 'sex' synonymous with heterosexual penetrative intercourse with male on top of female, and it makes it difficult to imagine PwDs able to have sex, because of their impairments.It is hypothesized that these myths and stereotypes influence the attitudes of people in general and, specifically, of parents or caregivers who care for PwDs.

Evidence also shows that attitudes towards PwDs also differ by type of disability, with those with more visible disabilities[3] or people with psychical disabilities (PwPSYDs) often facing greater discrimination with respect to persons with physical disabilities (PwPHDs)[9]. PwPSYDs are deemed unable to provide valid consent[10], to marry or have children [11], or, far from being angelic, to be hypersexual, unable to control theirselves, devoid of any inhibition, irresponsible and sometimes perverse[12]. Sexual stigma has a negative impact on opportunities for intimate relationships, procreation, sexual education and sexual health. Sexuality is often discouraged and inaccessible to many adults with disabilities. PwDs often lack safe, private places to engage in partnered or individual sexual activities, and reproductive and parenting rights of PwDs, and in particular for PwPSYDs are often viewed negatively by family members, service providers, and the general community[13,14]. Moreover, PwDs are particularly at risk of coercion or of undergoing sterilization or contraceptive procedures, such as intrauterine device (IUD) insertion without their free and fully informed choice and consent. This is especially the case for women with major or multiple impairments or with PSYDs[15]

Some authors tried to inquire which personal characteristics of the population affect attitudes regarding sexuality in PwDs, with inconsistent results, plausibly due to methodological and sample differences. Some studies suggest an effect of age, with older people expressing less accepting positions[16-18], while others failed to find an association between acceptance and age[19,20]. Similarly, while some evidence exist that females displayed more positive attitudes related to sex and disability[20,21], others revealed that males held more liberal opinions [22] and one showed no relationship between gender and attitude towards sexuality[18]. As regards education, some studies revealed an association between higher levels of instruction and more positive attitudes[23], while others showed no relationship [19,20,24]. Attitudes towards sexuality in PwDs may also vary due to beliefs associated with cultural origin $[3,25,26]$ and religion with more religious people tending to hold more conservative opinions [23]. However, most studies on attitudes towards the SRs of PwDs have engaged primarily their family members, supporting staff or university students, while a few updated data exist in relation to samples from the general population[3,25,27].

In Italy, serious issues of prejudice and discrimination against minorities exist, to the point that a bill is being examined by Parliament seeking to punish acts of discrimination 
and incitement to violence against gay, lesbian, transgender and PwDs[28]. Our previous study indicated that SRs are less recognized in minorities such as LGB people[29]. As far as we know, no recent studies in Italy inquired the societal level of agreement with the SRs of PwPHDs and PwPSYD, or the socio-demographic predictors of a more unfavourable attitude.

The aim of this study was therefore to analyze the level of agreement of the Italian general population with the SR of PwPHDs and PwPSYDs to have a satisfactory sexuality, to marry and to adopt a child, and to evaluate whether the SR of PwPSYDs were subject to less recognition, compared to PwPHDs. Further objective was to better understand which socio-demographic characteristics of Italian people significantly associated with lower agreement with the SR for PwPHDS and PwPSYDs.

\section{Materials and Methods}

\section{Study design and description}

The data reported in this paper is extracted from a larger, original study which cross-sectionally investigated attitudes of Italian people regarding the right of particular minorities or demographic categories (i.e. heterosexual, homosexual, bisexual and transsexual men, women or couples; PwPHDs; PwPSYDs, minors; seniors; sex-workers) to have a satisfying sexuality, to marry, to adopt children, to be hired for any job and to be free to live their sexuality[30].

The study was approved by the Scientific Committee of the Italian Federation of Scientific Sexology (FISS) and carried out in cooperation between the Youth Section of FISS (FISS Youth) and the Youth Initiative Committee of the World Association of Sexual Health (WAS YIC). An internet-based anonymous questionnaire was developed with Google Forms (Google LLC, Mountain View, CA, USA) to collect information related to socio-demographic data of respondents and level of agreement with statements related to the abovementioned SRs.

The questionnaire was distributed through the main social media by all the authors and by colleagues affiliated with their associations, through a snowball sampling approach, and published on the website of the Italian Federation of Scientific Sexology (www.fissonline.it). The first page of the form presented the proponent Institutions, explained the rationale, objectives and contents of the survey, and advised that the survey was reserved exclusively for people aged 18 or over. 'I agree' or 'I do not agree' options on the first page of the questionnaire were used in lieu of a signature, to provide informed consent. People who did not accept to participate were redirected to the last page of the form and thanked for their potential interest, while those who accepted accessed the survey.

\section{Inclusion/exclusion criteria}

The questionnaire was designed to be proposed to the entire Italian adult population. Therefore, the only criterion for inclusion/exclusion was having reached the age of majority, in accordance with Italian laws.

\section{Specific contents of the questionnaire}

Two main kinds of information were considered:

(a) socio-demographic information: age in years (categorized in three groups of comparable size) ; biological sex (female, male); education (undergraduated, graduated, post-graduated); region of origin (open question, which was recoded in coming from North, Center or South-Islands); occupational status (student, employed or unemployed/retired); sexual orientation (completely heterosexual, mostly heterosexual, bisexual, mostly homosexual and completely homosexual, which was recoded in 'completely or not-completely heterosexual'); relational status (single, in a committed relationship, cohabiting with a partner, married); religiosity (non-believer, believer, practicing); kind of religion (multiple choice with free field to enter non-prefilled data). 
(b) the level of agreement with the right for PwPHDs, and PwPSYDs to have a satisfying sexuality, to marry and to adopt children, coded on a 6-point likert-type scale, $(1=$ complete disagreement; 2 = moderate disagreement; $3=$ mild disagreement; $4=$ mild agreement; $5=$ moderate agreement; $6=$ complete agreement). In order to prompt to a stance, it was not possible to express intermediate opinions between agreement and disagreement or to avoid answering one or more questions.

\section{Statistical analyses}

All analyses were performed with IBM SPSS version 20 (SPSS Inc. Chicago, IL, USA). Descriptive analyses included calculation of the mean \pm standard deviations for continuous variables, and absolute frequencies and percentages for categorical ones. The Shapiro-Wilk test was performed in order to evaluate the normality of distributions.

Since answers to most questions about SRs were highly skewed towards higher scores, the Wilcoxon matched pairs test was used to compare, the levels of agreement with the right of PwPHDs and PwPSYDs to each SR.

Multiple ordinal regression models failed to respect the assumption of proportional odds, due to a large number of empty cells. Therefore, answers to questions related to the SRs were dichotomized (a score of 1,2 or 3 was classified as "disagreement" and a score of 4, 5, 6 as "agreement") and multiple binary logistic regression analyses were conducted to identify those socio-demographic variables which associated with "agreement" with each SR for PwPHDs and PwPSYDs, taking "disagreement" as a reference. Values were expressed as odds ratio (OR) and 95\% confidence intervals (95\% CI).

The level of significance was established at $95 \%(\mathrm{p}<0.05)$ for all statistical analyses.

In order to exclude multicollinearity, the Variance Inflation Factor (VIF) was calculated for each predictor. Dummy variables were obtained from non dicothomous ones and calculated by selecting for reference the most prevalent category. A VIF greater than 2.5 (which corresponds to an $\mathrm{R}^{2}$ of .60) was considered indicative of multicollinearity.

\section{Results}

\subsection{Descriptives}

One thousand and seven out of 1015 people who had accessed the questionnaire provided informed consent to the research. Of these, 34 (3.4\%) were excluded from further analyses because they belonged, were born, or resided in countries other than Italy.

The analyzed sample was therefore composed of 973 participants, aged between 18 and 84 years (mean age: $35.5 \pm 11.7$; median age: 33.0 ). More than two thirds of them were female $(71.1 \%)$ and people under 40 (70.5\%). Middle-aged and seniors (people over 50) represented $12.4 \%$ of the sample. Graduates and post-graduates constituted $65.9 \%$ of the sample, which was made for $29.3 \%$ by Medical Doctors or Psychologists. Demographics are shown in detail in table 1. Four-hundred and eighty-two out of 509 participants declaring themselves non-atheists were catholics (94.6\%), therefore, due to the low presence of non-catholic responders, 'kind of religion' was excluded from potential predictors of 'agreement'.

\subsection{The SR of PwPHDs and PwPSYDs to have satisfactory sexuality}

\subsubsection{Percentages of agreement and comparison between PwPHDs and PwPSYDs}

Overall, more than $85 \%$ of the sample declared in agreement with the SR of PwDs to have a satisfactory sexuality (Graph 1). Only $1.1 \%, 1.4 \%$, and $2.4 \%$ of participants answered being completely, moderately or mildly opposed to this SR for PwPHDs, while $4.1 \%, 8.9 \%$ and $82.0 \%$ declared mildly, moderately or completely in favor. A slightly lower number of respondents expressed complete, moderate or slight agreement with the 
right of PwPSYDs to have a satisfactory sexuality $(63.4 \%, 11.4 \%$, and $10.8 \%$, respectively), while $7.9 \%, 2.8 \%$ and $3.7 \%$ were mildly, moderately or completely opposed.

The Wilcoxon Signed-Ranks Test indicated that the median ranks for PwPHDs were statistically significantly higher than the median ranks for PwPSYDs $(Z=13.04 \mathrm{p}<.001)$.

3.1.2. Socio-demographic variables associated with agreement with PwPHDs's right to have a satisfactory sexuality

The results of the univariate logistic regression analyses suggested the existence of an association between demographics, such as sex, education, occupation and relational status, and agreement with the SR of people with PhD to have a satisfactory sexuality (table 2), while the multiple logistic regression analysis, indicated that only positive associations between 'agreement' and sex were maintained, when taking into account other potential predictors. Women agreed in significantly higher percentages than men $(96.1 \%$ vs $92.5 \%$ ) with the right of PwPHDs to have a satisfying sexuality (O.R. $=2.11$; 95\% C.I.: $1.11-4.01 ; \mathrm{p}=0.022)$.

3.1.3. Socio-demographic variables associated with agreement with PwPSYDs's right to have a satisfactory sexuality

The results of the univariate logistic regression analyses suggested the existence of an association between agreement with the SR of people with PSYDs to have a satisfactory sexuality and sex, religion, regional origin, occupational status, relational condition and level of education (table 2). Most of these associations maintained statistical significance in the multivariate model. In particular, being female, atheist, graduated, employed or student and living with a partner were related to higher odds for agreement than being male (O.R. =1.55; 95\% C.I.: $1.03-2.35 ; \mathrm{p}=0.038)$, believer (O.R. $=1.82 ; 95 \%$ C.I.: $1.18-2.82 ; \mathrm{p}=0.007)$ or churchgoer (O.R. $=2.25 ; 95 \%$ C.I.: $1.3-3.89 ; \mathrm{p}=0.004)$, undergraduated (O.R. = 1.73; 95\% C.I.: $1.1-2.72 ; \mathrm{p}=0.019)$, unemployed (employed: O.R. = 1.92; 95\% C.I.: $1.18-3.11 ; \mathrm{p}=0.008$; student: O.R. $=2.47 ; 95 \%$ C.I.: $1.27-4.81 ; \mathrm{p}=0.008)$, or single (cohabitant: O.R. $=1.92 ; 95 \%$ C.I.: $1.06-3.48 ; \mathrm{p}=0.032$; married: O.R. $=1.87 ; 95 \%$ C.I.: $1.11-3.17 ; \mathrm{p}=0.019)$, respectively, while regional origin resulted in an association that was bordering on statistical significance (O.R. $=1.59 ; 95 \%$ C.I.: $1-2.54 ; p=0.051)$.

\subsection{The SR of PwPHDs and PwPSYDs to get married}

\subsubsection{Percentages of agreement and comparison between PwPHDs and PwPSYDs}

Overall, 98.3\% participants declared in agreement with the right of PwPHDs to marry, while $78.7 \%$ of them answered being favourable to marriage for PwPSYD (Graph 1). In particular, $88.8 \%$ participants expressed strong agreement with the possibility fot PwHDs to get married, while $6.7 \%$ and $2.8 \%$ declared moderately and mildly in favour, and only $1.7 \%$ expressed disagreement. A noticeable lower number of respondents expressed complete, moderate or slight agreement with the right of PwPSYDs to marry $(51.1 \%, 11.9 \%$, and $15.7 \%$, respectively), while $11.3 \%, 4.7 \%$ and $5.2 \%$ were mildly, moderately or completely opposed (Graph 1).

The Wilcoxon Signed-Ranks Test indicated that the median ranks for PwPHDs were statistically significantly higher than the median ranks for PwPSYDs $(Z=17.85 \mathrm{p}<.001)$. 3.3.2. Socio-demographic variables associated with agreement with PwPHDs's right to get married

3.3.2. Socio-demographic variables associated with agreement with PwPHDs's right to get married

The results of the logistic regression analyses are to interpret with caution, due to the extremely low number of people against marriage for PwPHDs in our sample (Table 3). Atheists/agnostics agreed in significantly higher percentages than churchgoers $(99.6 \%$ vs 95.9\%) with the right of PwPHDs to marry, and a positive significant association seemed to exist between 'agreement' and religiosity in multiple regression analysis (O.R. = 7.22; 95\% C.I.: 1.32 - 39.62; $\mathrm{p}=0.023$ ). 
3.3.3. Socio-demographic variables associated with agreement with PwPSYDs's right to get married

The results of the univariate logistic regression analyses suggested the existence of an association between agreement with the SR of people with PSYDs to marry and all considered predictors, with the exception of provenance (table 3). Most of these associations maintained statistical significance in the multivariate model. In particular, being female, atheist/agnostic, post-graduated, student and non (completely) heterosexual were related to higher odds for agreement than being male (O.R. $=1.83$; 95\% C.I.: 1.28 2.63; $\mathrm{p}=0.001)$, believer (O.R. $=1.47 ; 95 \%$ C.I.: $1.01-2.16 ; \mathrm{p}=0.046)$ or churchgoer (O.R. $=$ 2.62; 95\% C.I.: 1.65 - 4.17; $\mathrm{p}<0.001$ ), undergraduated (O.R. $=1.9 ; 95 \%$ C.I.: 1.21 - 2.98; $\mathrm{p}=$ 0.005), unemployed (O.R. $=2.31 ; 95 \%$ C.I.: $1.2-4.43 ; \mathrm{p}=0.012)$, or heterosexual (O.R. = $1.81 ; 95 \%$ C.I.: $1.13-2.88 ; \mathrm{p}=0.013)$.

\subsection{The SR of PwPHDs and PwPSYDs to adopt a child}

\subsubsection{Percentages of agreement and comparison between PwPHDs and PwPSYDs}

The SR of PwDs to adopt a child encountered the agreement of $71.7 \%$ of the sample, while $21.8 \%$ of respondents declared being favourable all'adozione di un bambino da parte delle PwPSYDs (Graph 1). 5.1\%, 3.1\%, and 10.1\% of participants answered being completely, moderately or mildly opposed to this SR for PwPHDs, while 14.7\%, 17.9\% and $49.1 \%$ declared mildly, moderately or completely in favor. A noticeable lower number of respondents expressed complete, moderate or slight agreement with the right of PwPSYDs adopt $(6.0 \%, 3.5 \%$, and $12.3 \%$, respectively), while $21.1 \%, 19.7 \%$ and $37.4 \%$ were mildly, moderately or completely opposed.

The Wilcoxon Signed-Ranks Test indicated that the median ranks for PwPHDs were statistically significantly higher than the median ranks for PwPSYDs $(Z=24.57 \mathrm{p}<.001)$.

3.4.2. Socio-demographic variables associated with agreement with PwPHDs's right to adopt a child

The results of the univariate logistic regression analyses suggested the existence of an association between education, religiosity, sexual orientation and relational status, and agreement with the SR of people with $\mathrm{PhD}$ to adopt a child (table 4). In the multiple logistic regression analysis, indicated that positive associations were maintained between 'agreement' and education and sexual orientation, when taking into account other potential predictors. Post-graduates and non (completely) heterosexuals agreed in significantly higher percentages than undergraduates (O.R. $=1.84 ; 95 \%$ C.I.: $1.14-2.98 ; \mathrm{p}=$ 0.013 ) and heterosexual people (O.R. $=2.03 ; 95 \%$ C.I.: $1.26-3.27 ; \mathrm{p}=0.004)$ with the right of PwPHDs to adopt a child.

3.4.3. Socio-demographic variables associated with agreement with PwPSYDs's right to adopt a child

The results of the univariate logistic regression analyses suggested the existence of an association between agreement with the SR of people with PSYDs to adopt a child and age, sexual orientation religion, and level of education (table 4). These two latter maintained statistical significance in the multivariate model. Indeed, being post-graduated and atheist/agnostic were related to higher odds for agreement than being undergraduated $($ O.R. $=1.97 ; 95 \%$ C.I.: $1.26-3.08 ; \mathrm{p}=0.003)$, or churchgoer $($ O.R. $=2.28 ; 95 \%$ C.I.: $1.3-$ 3.99; $\mathrm{p}=0.004)$. 
3.4. Figures, Tables and Schemes

Table 1. Descriptive statistics.

\begin{tabular}{|c|c|c|}
\hline Sample Characteristics & Variable levels & Frequencies (\%) \\
\hline \multirow[t]{2}{*}{ Sex } & Male & $281(28.9)$ \\
\hline & Female & $692(71.1)$ \\
\hline \multirow[t]{3}{*}{ Age } & $18-29$ & $348(35.8)$ \\
\hline & $30-39$ & $338(34.7)$ \\
\hline & 40 or more & $287(29.5)$ \\
\hline \multirow[t]{3}{*}{ Provenience } & North & $390(40.1)$ \\
\hline & Center & $314(32.3)$ \\
\hline & South and Islands & $269(27.6)$ \\
\hline \multirow[t]{3}{*}{ Education } & Undergraduate & $332(34.1)$ \\
\hline & Graduate & $391(40.2)$ \\
\hline & Post-graduate & $250(25.7)$ \\
\hline \multirow[t]{3}{*}{ Occupation } & Student & $206(21.2)$ \\
\hline & Employed & $620(63.7)$ \\
\hline & Unemployed or retired & $147(15.1)$ \\
\hline \multirow[t]{4}{*}{ Relational status } & Single & $285(29.3)$ \\
\hline & In a committed relationship & $260(26.7)$ \\
\hline & Cohabiting with partner & $190(19.5)$ \\
\hline & Married & $238(24.5)$ \\
\hline \multirow[t]{3}{*}{ Religiosity } & Atheist/agnostic & $464(47.7)$ \\
\hline & Believer & $361(37.2)$ \\
\hline & Churchgoer & $148(15.2)$ \\
\hline \multirow[t]{2}{*}{ Sexual orientation } & Heterosexual & $730(75.0)$ \\
\hline & $\begin{array}{l}\text { Not-completely heterosexual, } \\
\text { homosexual, bisexual or queer }\end{array}$ & $243(25.0)$ \\
\hline
\end{tabular}


Figure 1. Distribution of responses inquiring agreement with the sexual rights of people with physical disabilities (PHDs) and Psychical disabilities (PSYDs) to have satisfactory sexuality, to get married, and to adopt a child. The light gray columns with black labels represent the agreement responses. The dark gray columns with white labels represent the disagreement responses. Labels are presented only for response options chosen by at least $2 \%$ of participants.

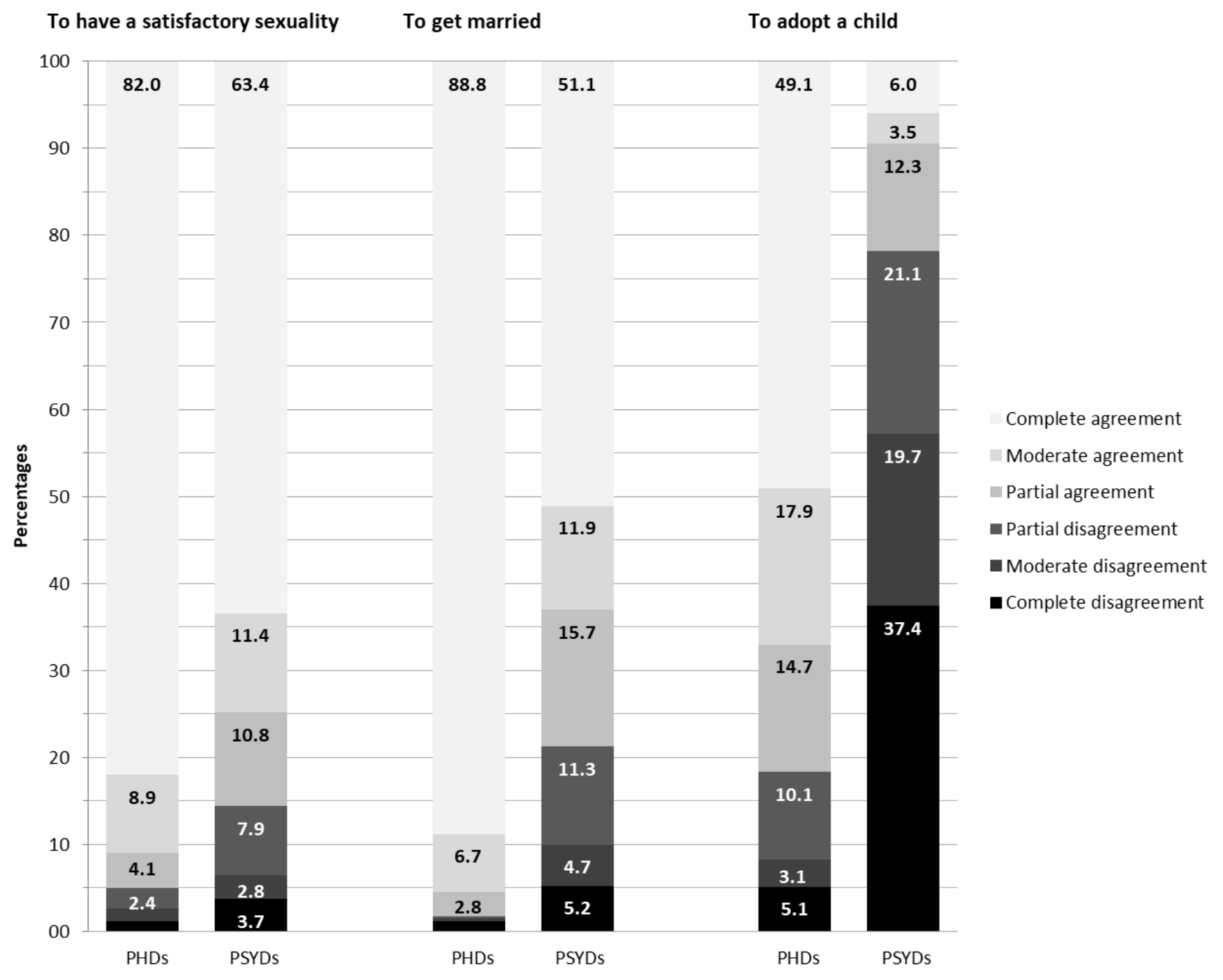


Table 2. Socio-demographic features and percentages of agreement with the right of people with Physical and Psychical disabilities to have a satisfactory sexuality: Frequencies (in percentages) and results of the univariate and multiple logistic regression analyses. Significant differences with respect to the reference are reported in bold.

\begin{tabular}{|c|c|c|c|c|c|c|c|c|c|c|c|}
\hline \multirow{3}{*}{\multicolumn{2}{|c|}{$\begin{array}{l}\text { Agreement with the right of people } \\
\text { with disabilities to have } \\
\text { a satisfactory sexuality }\end{array}$}} & \multicolumn{5}{|c|}{ People with Physical Disabilities } & \multicolumn{5}{|c|}{ People with Psychical Disabilities } \\
\hline & & \multirow[b]{2}{*}{ Freq $\%$} & \multicolumn{2}{|l|}{ Univariate LR } & \multicolumn{2}{|l|}{ Multiple LR } & \multirow[b]{2}{*}{ Freq $\%$} & \multicolumn{2}{|l|}{ Univariate LR } & \multicolumn{2}{|l|}{ Multiple LR } \\
\hline & & & OR $(95 \% \mathrm{CI})$ & $\mathrm{p}$ & OR $(95 \% \mathrm{CI})$ & $\mathrm{p}$ & & OR $(95 \% \mathrm{CI})$ & $\mathrm{p}$ & OR $(95 \% \mathrm{CI})$ & $\mathrm{p}$ \\
\hline \multirow[t]{2}{*}{ Sex } & Male & 92.5 & - & - & - & - & 81.9 & - & - & - & - \\
\hline & Female & 96.1 & $1.99(1.11-3.58)$ & .022 & $2.11(1.11-4.01)$ & .022 & 87.1 & $1.5(1.03-2.19)$ & .034 & $1.55(1.03-2.35)$ & .038 \\
\hline \multirow[t]{3}{*}{ Age } & $18-29$ & 94.5 & - & - & - & - & 86.5 & - & - & - & - \\
\hline & $30-39$ & 95.0 & $1.09(.55-2.13)$ & .801 & $.76(.29-1.99)$ & .579 & 84.9 & $0.88(0.57-1.35)$ & .554 & $0.84(0.49-1.47)$ & .551 \\
\hline & 40 or more & 95.8 & $1.32(.63-2.78)$ & .458 & $1.40(.48-4.13)$ & .538 & 85.4 & $0.91(0.58-1.43)$ & .684 & $1.16(0.63-2.12)$ & .642 \\
\hline \multirow[t]{3}{*}{ Provenience } & North & 96.2 & - & - & - & - & 88.2 & - & - & - & - \\
\hline & Center & 94.3 & $.66(.33-1.33)$ & .242 & $.59(.28-1.24)$ & .164 & 86.0 & $0.82(0.53-1.28)$ & .382 & $0.74(0.46-1.19)$ & .221 \\
\hline & South and Islands & 94.4 & $.68(.33-1.41)$ & .298 & $.80(.37-2.01)$ & .584 & 81.4 & $0.59(0.38-0.90)$ & .016 & $0.63(0.39-1.00)$ & .051 \\
\hline \multirow[t]{3}{*}{ Instruction } & Undergraduate & 93.1 & - & - & - & - & 81.6 & - & - & - & - \\
\hline & Graduate & 96.9 & $2.35(1.15-4.80)$ & .019 & $1.91(.89-4.08)$ & .096 & 88.5 & $1.73(1.14-2.63)$ & .010 & $1.73(1.1-2.72)$ & .019 \\
\hline & Post-graduate & 94.8 & $1.36(.68-2.74)$ & .393 & $.89(.39-2.01)$ & .777 & 86.4 & $1.43(0.91-2.26)$ & .124 & $1.42(0.85-2.36)$ & .179 \\
\hline \multirow[t]{3}{*}{ Occupation } & Unemployed-retired & 92.5 & - & - & - & - & 76.9 & - & - & - & - \\
\hline & Employed & 96.3 & $2.10(1.00-4.41)$ & .050 & $2.16(0.97-4.78)$ & .058 & 86.8 & $1.97(1.26-3.09)$ & .003 & $1.92(1.18-3.11)$ & .008 \\
\hline & Student & 93.2 & $1.11(.49-2.52)$ & .804 & $0.95(0.34-2.67)$ & .924 & 88.3 & $2.28(1.29-4.05)$ & .005 & $2.47(1.27-4.81)$ & .008 \\
\hline \multirow[t]{2}{*}{ Heterosexual } & Yes & 94.9 & - & - & - & - & 84.5 & - & - & - & - \\
\hline & Not completely/no & 95.5 & $1.13(.57-2.24)$ & .736 & $1.44(0.66-3.15)$ & .361 & 88.9 & $1.47(0.94-2.29)$ & .094 & $1.35(0.82-2.22)$ & .241 \\
\hline Relational & Single/casual partners & 94.5 & - & - & - & - & 80.7 & - & - & - & - \\
\hline \multirow[t]{3}{*}{ status } & In a committed relationship & 97.9 & $2.33(1.05-5.16)$ & .037 & $2.64(0.8-8.75)$ & .112 & 87.3 & $1.64(1.03-2.63)$ & .037 & $1.52(0.93-2.48)$ & .094 \\
\hline & Cohabiting with partner & 96.5 & $3.89(1.32-11.47)$ & .014 & $1.86(0.69-5.04)$ & .220 & 90.0 & $2.15(1.23-3.76)$ & .007 & $1.92(1.06-3.48)$ & .032 \\
\hline & Married & 92.3 & $1.45(.71-2.94)$ & .306 & $0.82(0.36-1.87)$ & .637 & 86.1 & $1.49(0.93-2.38)$ & .099 & $1.87(1.11-3.17)$ & .019 \\
\hline \multirow[t]{3}{*}{ Religiosity } & Atheist/agnostic & 95.5 & - & - & - & - & 89.9 & - & - & - & - \\
\hline & Believer & 94.5 & $.81(.43-1.51)$ & .808 & $0.77(0.39-1.52)$ & .450 & 82.5 & $0.53(0.36-0.8)$ & .002 & $0.55(0.36-0.85)$ & .007 \\
\hline & Churchgoer & 93.3 & $.96(.40-2.30)$ & .918 & $0.97(0.38-2.47)$ & .945 & 79.7 & $0.44(0.27-0.73)$ & .001 & $0.44(0.26-0.77)$ & .004 \\
\hline
\end{tabular}


LR: Logistic regression model; Freq \%: percentages; OR: odds ratio; 95 \% CI: 95 \% confidence interval; -: reference value; Not completely/no: not-completely heterosexual, homosexual, bisexual or queer 
Table 3. Socio-demographic features and percentages of agreement with the right of people with Physical and Psychical disabilities to get married: Frequencies (in percentages) and results of the univariate and multiple logistic regression analyses. Significant differences with respect to the reference are reported in bold.

\begin{tabular}{|c|c|c|c|c|c|c|c|c|c|c|c|}
\hline \multirow{3}{*}{\multicolumn{2}{|c|}{$\begin{array}{l}\text { Agreement with the right } \\
\text { of people with disabilities } \\
\text { to get married }\end{array}$}} & \multicolumn{5}{|c|}{ People with Physical Disabilities } & \multicolumn{5}{|c|}{ People with Psychical Disabilities } \\
\hline & & \multirow[b]{2}{*}{ Freq \% } & \multicolumn{2}{|l|}{ Univariate LR } & \multicolumn{2}{|l|}{ Multiple LR } & \multirow[b]{2}{*}{ Freq \% } & \multicolumn{2}{|l|}{ Univariate LR } & \multicolumn{2}{|l|}{ Multiple LR } \\
\hline & & & OR $(95 \%$ CI $)$ & $\mathrm{p}$ & OR $(95 \% \mathrm{CI})$ & $\mathrm{p}$ & & OR $(95 \%$ CI $)$ & $\mathrm{p}$ & OR $(95 \%$ CI $)$ & $\mathrm{p}$ \\
\hline \multirow[t]{2}{*}{ Sex } & Male & 97.2 & - & - & - & - & 71.2 & - & - & - & - \\
\hline & Female & 98.7 & $2.22(0.85-5.82)$ & .104 & $2.05(0.71-5.9)$ & .183 & 81.8 & $1.82(1.32-2.51)$ & .000 & $1.83(1.28-2.63)$ & .001 \\
\hline \multirow[t]{3}{*}{ Age } & $18-29$ & 100.0 & - & - & - & - & 86.2 & - & - & - & - \\
\hline & $30-39$ & 97.6 & - & - & - & - & 76.3 & $0.52(0.35-0.77)$ & .001 & $0.62(0.37-1.03)$ & .066 \\
\hline & 40 or more & 96.9 & $0.36(0.14-0.95)$ & .040 & $0.9(0.28-2.85)$ & .852 & 72.5 & $0.42(0.28-0.63)$ & .000 & $0.68(0.39-1.16)$ & .152 \\
\hline \multirow[t]{3}{*}{ Provenience } & North & 97.9 & - & - & - & - & 78.7 & - & - & - & - \\
\hline & Center & 98.7 & $1.62(0.48-5.44)$ & .433 & $1.13(0.3-4.18)$ & .856 & 81.8 & $1.22(0.84-1.77)$ & .302 & $1.03(0.69-1.55)$ & .869 \\
\hline & South and Islands & 98.1 & $1.11(0.36-3.42)$ & .861 & $0.96(0.28-3.27)$ & .952 & 75.1 & $0.82(0.56-1.18)$ & .276 & $0.76(0.51-1.14)$ & .182 \\
\hline \multirow[t]{3}{*}{ Instruction } & Undergraduate & 97.3 & - & - & - & - & 74.4 & - & - & - & - \\
\hline & Graduate & 98.7 & $2.15(0.71-6.48)$ & .174 & $1.45(0.42-4.99)$ & .557 & 80.6 & $1.43(1-2.03)$ & .048 & $1.35(0.91-1.99)$ & .134 \\
\hline & Post-graduate & 98.8 & $2.29(0.61-8.56)$ & .217 & $2.06(0.49-8.6)$ & .321 & 81.6 & $1.53(1.02-2.29)$ & .040 & $1.90(1.21-2.98)$ & .005 \\
\hline \multirow[t]{3}{*}{ Occupation } & Unemployed-retired & 96.6 & - & - & - & - & 73.5 & - & - & - & - \\
\hline & Employed & 98.2 & $1.95(0.67-5.7)$ & .223 & $1.9(0.6-5.98)$ & .272 & 76.6 & $1.18(0.78-1.78)$ & .423 & $1.32(0.84-2.07)$ & .224 \\
\hline & Student & 99.5 & $7.22(0.83-62.45)$ & .073 & $4.49(0.42-47.69)$ & .213 & 88.8 & $2.87(1.63-5.07)$ & .000 & $2.31(1.2-4.43)$ & .012 \\
\hline \multirow[t]{2}{*}{ Heterosexual } & Yes & 97.8 & - & - & - & - & 75.5 & - & - & - & - \\
\hline & Not completely/no & 99.6 & $5.42(0.72-41.11)$ & .102 & $2.37(0.27-20.54)$ & .434 & 88.5 & $2.49(1.63-3.83)$ & .000 & $1.81(1.13-2.88)$ & .013 \\
\hline Relational & Single/casual partners & 97.5 & - & - & - & - & 80.0 & - & - & - & - \\
\hline \multirow[t]{3}{*}{ status } & In a committed relationship & 99.6 & $6.52(0.8-53.37)$ & .080 & $4.96(0.58-42.2)$ & .143 & 80.4 & $1.02(0.67-1.56)$ & .910 & $0.81(0.52-1.28)$ & .373 \\
\hline & Cohabiting with partner & 99.5 & $4.76(0.58-39)$ & .146 & $3.39(0.38-29.87)$ & .271 & 83.7 & $1.28(0.79-2.08)$ & .312 & $1.12(0.66-1.88)$ & .680 \\
\hline & Married & 96.6 & $0.72(0.26-2.03)$ & .538 & $1.18(0.39-3.63)$ & .768 & 71.4 & $0.63(0.42-0.94)$ & .023 & $0.93(0.59-1.47)$ & .765 \\
\hline \multirow[t]{3}{*}{ Religiosity } & Atheist/agnostic & 99.6 & - & - & - & - & 84.9 & - & - & - & - \\
\hline & Believer & 97.5 & $0.17(0.04-0.79)$ & .024 & $0.22(0.04-1.08)$ & .062 & 76.7 & $0.59(0.41-0.83)$ & .003 & $0.68(0.46-0.99)$ & .046 \\
\hline & Churchgoer & 95.9 & $0.1(0.02-0.51)$ & .006 & $0.14(0.03-0.76)$ & .023 & 64.2 & $0.32(0.21-0.49)$ & .000 & $0.38(0.24-0.61)$ & .000 \\
\hline
\end{tabular}


LR: Logistic regression model; Freq \%: percentages; OR: odds ratio; 95 \% CI: 95 \% confidence interval; -: reference value; Not completely/no: not-completely

LR: Logistic regression model; Freq \%: perc
heterosexual, homosexual, bisexual or queer

\section{西}


Table 4. Socio-demographic features and percentages of agreement with the right of people with Physical and Psychical disabilities to adopt a child: Frequencies (in percentages) and results of the univariate and multiple logistic regression analyses. Significant differences with respect to the reference are reported in bold.

\begin{tabular}{|c|c|c|c|c|c|c|c|c|c|c|c|}
\hline \multirow{2}{*}{\multicolumn{2}{|c|}{$\begin{array}{l}\text { Agreement with the right of people } \\
\text { with disabilities to adopt a child }\end{array}$}} & \multicolumn{5}{|c|}{ People with Physical Disabilities } & \multicolumn{5}{|c|}{ People with Psychical Disabilities } \\
\hline & & \multirow[b]{2}{*}{ Freq $\%$} & \multicolumn{2}{|l|}{ Univariate LR } & \multicolumn{2}{|l|}{ Multiple LR } & \multirow[b]{2}{*}{ Freq \% } & \multicolumn{2}{|l|}{ Univariate LR } & \multicolumn{2}{|l|}{ Multiple LR } \\
\hline & & & OR $(95 \%$ CI) & $\mathrm{p}$ & OR $(95 \% \mathrm{CI})$ & $\mathrm{p}$ & & OR $(95 \% \mathrm{CI})$ & $\mathrm{p}$ & OR $(95 \% \mathrm{CI})$ & $\mathrm{p}$ \\
\hline \multirow[t]{2}{*}{ Sex } & Male & 81.1 & - & - & - & - & 19.9 & - & - & - & - \\
\hline & Female & 81.9 & $1.05(0.74-1.51)$ & .771 & $0.99(0.67-1.46)$ & .949 & 22.5 & $1.17(0.83-1.65)$ & .371 & $1.05(0.73-1.52)$ & .800 \\
\hline \multirow[t]{3}{*}{ Age } & $18-29$ & 81.6 & - & - & - & - & 25.9 & - & - & - & - \\
\hline & $30-39$ & 84.0 & $1.19(0.8-1.76)$ & .402 & $1.29(0.77-2.14)$ & .332 & 20.7 & $0.75(0.52-1.07)$ & .111 & $0.84(0.53-1.34)$ & .465 \\
\hline & 40 or more & 79.1 & $0.85(0.58-1.26)$ & .426 & $1.17(0.68-2.00)$ & .576 & 18.1 & $0.63(0.43-0.93)$ & .020 & $0.83(0.49-1.40$ & .486 \\
\hline \multirow[t]{3}{*}{ Provenience } & North & 82.6 & - & - & - & - & 21.8 & - & - & - & - \\
\hline & Center & 84.1 & $1.12(0.75-1.66)$ & .593 & $1.04(0.68-1.58)$ & .853 & 23.9 & $1.13(0.79-1.6)$ & .511 & $1.07(0.74-1.55)$ & .712 \\
\hline & South and Islands & 77.7 & $0.74(0.5-1.08)$ & .121 & $0.74(0.49-1.11)$ & .144 & 19.3 & $0.86(0.58-1.27)$ & .444 & $0.86(0.58-1.29)$ & .479 \\
\hline \multirow[t]{3}{*}{ Instruction } & Undergraduate & 77.4 & - & - & - & - & 17.8 & - & - & - & - \\
\hline & Graduate & 82.6 & $1.39(0.96-2)$ & .081 & $1.37(0.92-2.04)$ & .118 & 22.8 & $1.36(0.94-1.97)$ & .098 & $1.43(0.97-2.11)$ & .074 \\
\hline & Post-graduate & 86.0 & $1.79(1.15-2.78)$ & .009 & $1.84(1.14-2.98)$ & .013 & 25.6 & $1.59(1.07-2.37)$ & .023 & $1.97(1.26-3.08)$ & .003 \\
\hline \multirow[t]{3}{*}{ Occupation } & Unemployed-retired & 77.6 & - & - & - & - & 21.8 & - & - & - & - \\
\hline & Employed & 82.1 & $1.33(0.86-2.06)$ & .206 & $1.14(0.71-1.81)$ & .590 & 19.5 & $0.87(0.56-1.35)$ & .539 & $0.82(0.51-1.30)$ & .395 \\
\hline & Student & 83.5 & $1.46(0.86-2.5)$ & .162 & $1.51(0.82-2.78)$ & .186 & 28.6 & $1.44(0.88-2.37)$ & .147 & $1.51(0.87-2.65)$ & .146 \\
\hline \multirow[t]{2}{*}{ Heterosexual } & Yes & 79.2 & - & - & - & - & 20.3 & - & - & - & - \\
\hline & Not completely/no & 89.3 & $2.19(1.41-3.42)$ & .001 & $2.03(1.26-3.27)$ & .004 & 26.3 & $1.41(1-1.97)$ & .048 & $1.16(0.8-1.68)$ & .430 \\
\hline \multirow{4}{*}{$\begin{array}{l}\text { Relational } \\
\text { status }\end{array}$} & Single/casual partners & 79.3 & - & - & - & - & 20.4 & - & - & - & - \\
\hline & In a committed relationship & 83.1 & $1.28(0.83-1.98)$ & .261 & $1.28(0.82-2.01)$ & .280 & 21.9 & $1.1(0.73-1.66)$ & .653 & $0.98(0.64-1.50)$ & .917 \\
\hline & Cohabiting with partner & 87.9 & $1.90(1.13-3.19)$ & .016 & $1.7(0.98-2.96)$ & .061 & 26.8 & $1.44(0.93-2.21)$ & .100 & $1.42(0.89-2.26)$ & .145 \\
\hline & Married & 78.2 & $0.93(0.61-1.42)$ & .749 & $1.05(0.66-1.68)$ & .835 & 19.3 & $0.94(0.61-1.44)$ & .770 & $1.29(0.79-2.10)$ & .314 \\
\hline \multirow[t]{3}{*}{ Religiosity } & Atheist/agnostic & 85.6 & - & - & - & - & 26.1 & - & - & - & - \\
\hline & Believer & 77.6 & $0.58(0.41-0.83)$ & .003 & $0.72(0.49-1.05)$ & .089 & 20.2 & $0.72(0.52-1)$ & .050 & $0.79(0.55-1.12)$ & .181 \\
\hline & Churchgoer & 79.7 & $0.66(0.41-1.07)$ & .092 & $0.88(0.53-1.47)$ & .623 & 12.2 & $0.39(0.23-0.67)$ & .001 & $0.44(0.25-0.77)$ & .004 \\
\hline
\end{tabular}


LR: Logistic regression model; Freq \%: percentages; OR: odds ratio; $95 \%$ CI: $95 \%$ confidence interval; -: reference value; Not completely/no: not-completely
heterosexual, homosexual, bisexual or queer

LR: Logistic regression model; Freq \%: percentages; OR: odds ratio; $95 \%$ CI: $95 \%$ confidence interval; -: reference value; Not completely/no: not-completely
heterosexual, homosexual, bisexual or queer $-$

doi:10.20944/preprints202110.0391.v1

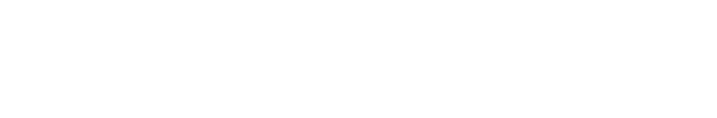

(1)

(1)




\section{Discussion}

To our knowledge, this is the first published research to inquire the levels of agreement with the SRs of PwDs in the Italian general population and the socio-demographic variables which may associate to positive or negative attitudes. The results of this study indicate that in very large majority Italians declared themselves in agreement with the right of PwPHDs to have a satisfactory sexuality and to marry, and mostly inclined to express agreement with their right to adopt a child, albeit to a lesser extent. Consistent to other research, the percentage of people who disagreed with these SRs when related to PwPSYDs was significantly higher[9], reaching almost $80 \%$ for adoption. Indeed, sexuality of PwPSYDs was foud to be judged as less appropriate than that of persons without any disability or with physical disabilities, since PwPSYDs elicit stereotypes of inability of judgment and control, impredictability and danger, resulting in false beliefs about unsafe sex, promiscuity or abuse[9].

Coherently with other studies[16,17], Italians' views about adoption in both categories of PwDs were more unfavourable than for sexuality and marriage, confirming that participants considered this aspect to be more complex and to perhaps have implications beyond the mere SRs of the individuals and requires abilities that many would judge to be beyond those of PwDs, and, in particular, of PwPSYDs. Differently to another study by Cuskelly and Gilmore[16], who had observed less favorable, yet still substantially positive, attitudes about parenting in PwPSYDs, Italian respondents declared themselves for the most tendentially or completely opposite to adoption by PwPSYDs. This difference could also be amplified by the fact that the present research requires a specific opinion on adoption and not on the general possibility of being parents.

Consistent with other research, women appeared to be more supportive of PwDs' SR to have a satisfactory sexuality and of PwPSYDs' SR to marry than men, while no differences between genders were observed in relation to parenting[20,21].

Regarding socio-demographic variables, our data revealed that religion was a strong predictor of negative attitudes in relation to the SRs of PwDs, with churchgoers as the most uncompromising category. Indeed,religious culture, with a "religious ethical model" has contributed in the past to the structuring of "false myths" about disability, supporting the opinion that a disabled body or mind is an indication of an inner (moral) ugliness (sin); therefore, the myth of a physical perfection that recalls purity and divine goodness, of very ancient memory, is very often found at the basis of prejudices on the causes of the impairment[6].

We found also a relationship between the level of education and the presence of agreement in relation to the SRs of the PwDs. In general, we observed that undergraduates tended to express more disagreement than graduates and post-graduates with SRs of PwDs. However, post-graduate people also tended to agree to a greater extent than undergraduates, albeit to a lesser extent than graduates. This trend can be explained by considering that, in our sample, medical doctors and psychologists represented up to $44.4 \%$ of post-graduates. Other research revealed that students and professionals who had frequent contact with PwPSYDs generally had more negative attitudes compared to those who had less experience with them [31].

In most comparisons we observed that the proportion of people in agreement with the SRs of the PwDs decreased with increasing age. However, in most univariate and multivariate analyses age did not appear to be a significant predictor of agreement, contrary to what has been reported in some literature which indicated age as an important predictor of negative attitudes towards the sexuality of PwD and in particular of those with intellectual disabilities. In any case, it is necessary to consider that our sample was mainly constituted by young people. Therefore, middle-aged and elderly people could be under-represented.

Sexual orientation was significant in predicting attitudes towards marriage and adoption, with not completely heterosexuals agreeing in a significantly higher percent- 
age than heterosexuals $(88.5 \%$ vs $75.5 \%)$ to these SRs. To our knowledge, there are no other studies that have investigated sexual orientation as a predictor for the SRs of PwDs. We can hypothesize that, given that in the period in which the survey was administered the question of the "Zan" law was much debated, non-heterosexual people were also much more sensitive to the issues of legitimizing unconventional couples or parenting for minorities.

\section{Conclusions}

Although its limitations, this study has important implications regarding PWDs' SRs in Italy. Firstly, even if quite positive opinions were expressed in most answers, important work is needed to overcome the cultural barriers that prevent PwDs from fully exercising their rights, in particular the right to adopt. Second, it was confirmed that PwPSYDs are the most discriminated. Actions are needed to overcome the prejudice and stigma towards them. Lastly, evidence is shown that certain characteristics of the population strongly affect the level of recognition of PwDs' SRs, in particular having strong religious beliefs is related to lower recognition. Other research demonstrated that specific training on sex and disability can lead to more positive attitudes related to their SRs [20]. For this reason, it is necessary to work specifically on populations with the highest risk factors for uncompromising attitudes, focusing efforts where possible on improving knowledge and overcoming stereotypes based on fears and ignorance. The normalization sexuality in disability should also be pursued through policies to disseminate correct and realistic knowledge.

Author Contributions: Conceptualization: SGDS, MC, MS, SE; methodology: SGDS, MC, MS.; software: SGDS; validation, MC and MS; formal analysis: SGDS; investigation: SGDS, MC, MS, VF, CM, CN, CR; data curation, SGDS; writing-original draft preparation, SGDS, MC, MS, GRG.; writing-review and editing, VF, CM, CN, CR, SE; supervision, MS and SE; All authors have read and agreed to the published version of the manuscript.

Funding: This research received no external funding.

Institutional Review Board Statement: The study was conducted according to the guidelines of the Declaration of Helsinki, and approved by the Scientific Committee of the Italian Federation of Sexology.

Informed Consent Statement: An opt-in approach was used in this research. Informed consent was requested upon fulfillment of the online survey. "I Agree" button allowed participants to click and begin answering the questionnaire, in order to collect their data online. If they do not agree to participate the study, they have the option to click an "I Do Not Agree" button so that their data was not submitted and collected online.

Conflicts of Interest: The authors declare no conflict of interest 


\section{References}

[1] World Report on Disability 2011, World Report on Disability, Last updated 2011, Accessed on 2011.

[2] Convention on the Rights of Persons with Disabilities and Optional Protocol UNITED NATIONS, Last updated 2006, Accessed on 2006.

[3] Devkota HR, Kett M, Groce N (2019) Societal attitude and behaviours towards women with disabilities in rural Nepal: Pregnancy, childbirth and motherhood. BMC Pregnancy Childbirth 19, 1-13.

[4] World Health Organization (2015) Sexual health, human rights and the law.

[5] Brodwin MG, Frederick PC (2010) Sexuality and societal beliefs regarding persons living with disabilities. J. Rehabil. 76, 3741.

[6] Stone SD (1995) The Myth of Bodily Perfection. Disabil. Soc.

[7] Shakespeare, Tom, Gillespie-Sells, Kath, Davies D (1996) Sexual Politics of Disability : Untold Desires.

[8] Milligan MS, Neufeldt AH (2001) The myth of asexuality: A survey of social and empirical evidence. Sex. Disabil.

[9] Hasson-Ohayon I, Hertz I, Vilchinsky N, Kravetz S (2014) Attitudes toward the sexuality of persons with physical versus psychiatric disabilities. Rehabil. Psychol. 59, 236-241.

[10] McGuire BE, Bayley AA (2011) Relationships, sexuality and decision-making capacity in people with an intellectual disability. Curr. Opin. Psychiatry 24, 398-402.

[11] Price J (2011) The Seeds of a Movement-Disabled Women and their Struggle to Organize. Toronto Assoc. Women's Rights 115.

[12] Giami A, Humbert C, Laval D (1983) L'ange et la bête: Représentations de la sexualité des handicapés mentaux chez les parents et les éducateurs., Editions de CTNERHI.

[13] Ditchman N, Kosyluk K, Lee EJ, Jones N (2016) How stigma affects the lives of people with intellectual disabilities: An overview. In Intellectual Disability and Stigma: Stepping Out from the Margins.

[14] Ditchman N, Easton AB, Batchos E, Rafajko S, Shah N (2017) The Impact of Culture on Attitudes Toward the Sexuality of People with Intellectual Disabilities. Sex. Disabil. 35, 245-260.

[15] Eliminating forced, coercive and otherwise involuntary sterilization An interagency statement.

[16] Cuskelly M, Gilmore L (2007) Attitudes to Sexuality Questionnaire (Individuals with an Intellectual Disability): Scale development and community norms. J. Intellect. Dev. Disabil. 32, 214-221.

[17] Cuskelly M, Bryde R (2004) Attitudes towards the sexuality of adults with an intellectual disability: Parents, support staff, and a community sample. J. Intellect. Dev. Disabil. 29, 255-264.

[18] Meaney-Tavares R, Gavidia-Payne S (2012) Staff characteristics and attitudes towards the sexuality of people with intellectual disability. J. Intellect. Dev. Disabil.

[19] Gilmore L, Chambers B (2010) Intellectual disability and sexuality: Attitudes of disability support staff and leisure industry employees. J. Intellect. Dev. Disabil.

[20] Pebdani RN (2016) Attitudes of Group Home Employees Towards the Sexuality of Individuals with Intellectual Disabilities. Sex. Disabil.

[21] Hunt X, Carew MT, Braathen SH, Swartz L, Chiwaula M, Rohleder P (2017) The sexual and reproductive rights and benefit derived from sexual and reproductive health services of people with physical disabilities in South Africa: Beliefs of non-disabled people. Reprod. Health Matters 25, 66-79.

[22] Trudel G, Desjardins G (1992) Staff reactions toward the sexual behaviors of people living in institutional settings. Sex. Disabil.

[23] Saxe A, Flanagan T (2014) Factors that impact support workers' perceptions of the sexuality of adults with developmental disabilities: A quantitative analysis. Sex. Disabil. 32, 45-63. 
[24] Bazzo G, Nota L, Soresi S, Ferrari L, Minnes P (2007) Attitudes of social service providers towards the sexuality of individuals with intellectual disability. J. Appl. Res. Intellect. Disabil.

[25] Sankhla D, Theodore K (2015) British Attitudes Towards Sexuality in Men and Women with Intellectual Disabilities: A Comparison Between White Westerners and South Asians. Sex. Disabil. 33, 429-445.

[26] Morales GEM, Ramirez EOL, Esterle M, Sastre MTM, Mullet E (2010) Judging the acceptability of sexual intercourse among people with learning DISABILities: A Mexico-france comparison. Sex. Disabil.

[27] Carew MT, Braathen SH, Hunt X, Swartz L, Rohleder P (2020) Predictors of negative beliefs toward the sexual rights and perceived sexual healthcare needs of people with physical disabilities in South Africa. Disabil. Rehabil. 42, 3664-3672.

[28] XVIII Legislatura - Lavori - Progetti di legge - Scheda del progetto di legge.

[29] Silvaggi M, Eleuteri S, Colombo M, Fava V, Malandrino C, Simone S, Nanini C, Rossetto C, Di Santo SG (2019) Attitudes towards the sexual rights of LGB people: Factors involved in recognition and denial. Sexologies.

[30] Silvaggi M, Di Santo SG, Artioli C, Colombo M, Fava V, Malandrino C, Melis I, Nanini C, Rossetto C, Simone S, Eleuteri S (2017) HP-02-005 Sexual rights of minorities in Italy: A snapshot of reality and sociodemographic characteristics involved in the recognition and denial. J. Sex. Med.

[31] Franco DG, Cardoso J, Neto I (2012) Attitudes towards affectivity and sexuality of people with intellectual disability. Sex. Disabil. 